\title{
EI destino de Juana de Lara, y la herencia del señorío de Vizcaya en los albores del periodo Trastámara
}

\author{
The Destiny of Juana de Lara, and the Inheritance of the \\ Lordship of Vizcaya on the Threshold of the Trastamara Period
}

\author{
Pablo Martín Prieto \\ Universidad Complutense. Madrid \\ pablomartinprieto@ghis.ucm.es
}

\begin{abstract}
RESUMEN
El presente trabajo plantea ciertos interrogantes fundamentales sobre la suerte de Juana de Lara, heredera de los señoríos de Lara y Vizcaya, quien, de acuerdo con las crónicas de López de Ayala, fue asesinada en tiempos del rey Pedro de Castilla, sin dejar sucesión. A pesar de esta información, cierta Juana de Lara - la verdadera o una impostora - apareció posteriormente conectada al poder en ascenso de la nueva monarquía Trastámara en 1366, en 1373 una dama del mismo nombre presentó una reclamación por la herencia de Vizcaya ante el Papa en Aviñón, y, casi al mismo tiempo, otra dama, la condesa de Alençon, presentó similares pretensiones ante Enrique II. Finalmente, Lara y Vizcaya quedaron incorporados al dominio directo de la corona castellana, y en realidad, si Juana de Lara sobrevivió o no a los tiempos de la "revolución Trastámara" continúa siendo un misterio sin resolver.
\end{abstract}

Palabras clave: Juana de Lara, Pedro I, Enrique II, Castilla, Vizcaya, Casa de Lara, Béarn, Siglo XIV.

\begin{abstract}
This paper poses crucial questions regarding the destiny of Juana de Lara, heiress to the estate of Lara and Vizcaya, who, according to Lopez de Ayala's chronicles, was killed during the reign of King Pedro of Castile, leaving no heir. In spite of this information, a certain Juana de Lara - the true one or an impostor - later appeared in connection with the rising power of the new Trastamara monarchy in 1366. In 1373 a lady by the same name raised a claim to the inheritance of Vizcaya before the Pope at Avignon, and, nearly at the same time, another lady, the countess of Alençon, presented Henry II with similar claims. Ultimately, Lara and Vizcaya were incorporated into the direct domains of the Castilian crown, and whether or not the real Juana de Lara survived the "Trastamara revolution" remains an unsolved mystery.
\end{abstract}

Key words: Juana de Lara, Pedro I, Enrique II, Castile, Vizcaya, Casa de Lara, Bearn, XIV ${ }^{\text {th }}$ Century.

Sumario: 1. Introducción. 2. Dramatis personae. 3. Sumario de los hechos según el Canciller Ayala. 4. El misterio de la "falsa Juana" de 1366. 5. 1373: Dos candidatas reclaman la sucesión de Vizcaya. 6. Conclusión. 


\section{INTRODUCCIÓN}

Como es bien sabido, el convulso reinado de Pedro I y el proceso de construcción, legitimación y asentamiento del nuevo poder Trastámara conforman un periodo singularmente movido, controvertido e interesante, hasta el punto de poder considerar la quiebra de la continuidad dinástica y la entronización de la nueva dinastía, tras el magnicidio de Montiel, como un verdadero punto de inflexión, decisivo por más de un motivo, en la historia de la Corona de Castilla. Entre los factores que contribuyen a explicar el interés especial que los principales acontecimientos políticos de esta época han suscitado en la consideración de los muchos y notables historiadores que se han ocupado del periodo, merece separada mención el detalle, el nervio e incluso la pasión que el canciller Ayala logró comunicar a la narración de la que sin duda constituye el tour de force de su labor como cronista, oficio para el que sin duda estaba muy dotado: la crónica de Pedro I y Enrique II, obra que comienza unitaria y a partir de un punto semeja bifurcarse para convertirse en dos ${ }^{1}$. La construcción aparentemente fácil pero muy meditada de esta obra mayor del canciller Ayala quizás esconde más de lo que revela sobre su proceso de elaboración, especialmente por lo que concierne al problema de la relación entre la inventio sobre las fuentes a las que su autor tuvo acceso, y el complejo ensamblado de los diversos materiales en un texto conservado en dos versiones principales, que desde los días de Jerónimo Zurita se consideran sucesivas y se conocen como Abreviada y Vulgar.

Bajo una apariencia de sereno "clasicismo", el estilo de Ayala, por lo general elegante e intemporal, es también portador, sin duda, de vetas reconocibles de intenso apasionamiento; en ciertos pasajes, la forma de disponer y cortar las noticias que narra parece ordenada a inducir determinadas valoraciones o efectos de naturaleza emocional en la mente del lector; algunas omisiones particularmente llamativas de su relato denuncian una intención parcial nada aséptica. Con todo, la impresión dominante entre quienes se han ocupado y se ocupan de la historia castellana de esta época es que el canciller Ayala puede considerarse un cronista razonablemente bien informado y veraz; si es influyente, lo es con justicia, y resulta inevitable volver una y otra vez a sus páginas para informarse y reflexionar sobre el periodo por él historiado ${ }^{2}$.

\footnotetext{
${ }^{1}$ OrdunA, Germán: “Crónica del rey don Pedro y del rey don Enrique su hermano, hijos del rey don Alfonso Onceno. Unidad de estructura e intencionalidad", en Actas del IX Congreso de la Asociación Internacional de Hispanistas (Berlín, agosto 1986) (S. NEUMEISTER, ed.), Francfurt a. M., 1989, t. I, pp. 255-262.

2 Pese al tiempo transcurrido, sigue pareciendo equilibrado el juicio de Juan Bautista SITGES, en su Las mujeres del rey don Pedro I de Castilla, Madrid, 1910, p. 17: "Muy discutida ha sido y aun es la crónica de Ayala, pero los cargos que contra ella se hacen, cuando se los examina fríamente, desvirtúan los acerbos ataques de que Ayala ha sido objeto. Los mismos que más le han censurado, como el Conde de la Roca, Ledo del Pozo, Guichot y otros, se ven obligados a seguirle. No quiere esto decir que Ayala sea impecable, ¿quién lo es? Pudo equivocarse y se equivocó, y aun faltó alguna vez a la verdad histórica; pero estos errores que todo historiador tiene, nacen del olvido de hechos transcurridos hace muchos años, o de no haberse enterado bien de ellos, sobre todo en el período que permaneció alejado de la corte de Don Pedro". Más recientemente, un gran conocedor del reinado de Pedro de Castilla emite un juicio global favorable sobre la veracidad como cronista de Ayala: "no se puede desautorizar en su conjunto la Crónica de Ayala, pues no se ha probado que exista el más mínimo dato de que haya podido falsear, de forma importante, su contenido": DíAz MARTíN, Luis Vicente: Pedro I el Cruel (1350-1369), Gijón, 2007, p. 16. Son muchos los estudios sobre la personalidad y obra cronística del canciller Ayala que podrían aquí citarse. Sólo a título de ejemplo: MeregaLLi, Franco: La
} 
En el presente trabajo nos proponemos acercarnos a la figura de una dama de la nobleza castellana de aquel tiempo, Juana de Lara, siguiendo en lo fundamental la cuenta que el canciller Ayala da de su trayectoria vital como una de las últimas representantes de la casa de Lara, al tiempo que la última señora de Vizcaya antes de su incorporación a la corona castellana. Mezclada en los turbios manejos de su esposo don Tello, medio hermano del rey Pedro y hermano de madre y padre del futuro Enrique II, a Juana le cupo un papel subalterno y atribulado como último eslabón de aquel histórico linaje al frente de Vizcaya, y, de acuerdo con la crónica del reinado, falleció sin descendencia, en prisión. Como en seguida veremos, lo más extraordinario y en cierta medida "misterioso" del destino de esta dama no se relaciona tanto con su pretendida, fugaz y rápidamente desmentida reaparición en la corte de Enrique II en 1366, episodio que Ayala refiere y es relativamente bien conocido, sino sobre todo con la posibilidad, que planteamos en nuestro trabajo, de que Juana de Lara sobreviviera al final de la guerra civil castellana y, tras reconstruir su vida, hubiera podido aspirar nuevamente a reanudar la continuidad dinástica de los Lara en el señorío de Vizcaya, posibilidad de la que existen ciertos indicios, los más notables y dignos de crédito conservados en los archivos vaticanos.

\section{DRAMATIS PERSONAE}

Antes de comenzar el seguimiento de la trayectoria vital de esta Juana de Lara, no estará de más, por propósitos de claridad, resumir una vez más lo principal del cuadro, suficientemente claro y asentado en la historiografía, de su entorno familiar inmediato ${ }^{3}$ :

1. Fernando de Castilla, llamado "de la Cerda" (II) (1275-1322) = Juana Núñez de Lara, llamada "la Palomilla" (1286-1351).

Hijos:

1.1. Juan Núñez de Lara (III), muerto en 1350 = María de Haro, Señora de Vizcaya. Hijos:

1.1.1. Lope de Lara, muerto sin hijos, en corta edad.

1.1.2. Nuño, Señor de Vizcaya, muerto en 1352, sin descendencia.

1.1.3. Juana de Lara, muerta supuestamente en $1359=$ Tello de Castilla, muerto en 1370 , sin descendencia legítima.

1.1.4. Isabel de Lara, muerta en 1361 = Juan, Infante de Aragón, muerto en 1358. Supuestamente, no hubo descendencia de este enlace.

vida política del canciller Ayala, Milán, 1955; SÁnchez Albornoz, Claudio: "El canciller Ayala, historiador", en Españoles ante la Historia, Buenos Aires, 1958, pp. 99-136; SuÁrez Fernández, Luis: El canciller Ayala y su tiempo, 1332-1407, Vitoria, 1962; GarcíA, Michel: Obra y personalidad del canciller Ayala, Madrid, 1982; Mitre Fernández, Emilio: "Tradición e innovación en la obra cronística del canciller Ayala", En la España medieval, 19 (1996) 51-75; OrdunA, G.: El arte narrativo y poético del canciller Ayala, Madrid, 1998; Estow, Clara: La legitimación de lo ilegítimo: López de Ayala y la historiografía medieval, Madrid, 2006.

${ }^{3}$ La justificación y pormenores de esta relación de personajes de la familia de los Lara puede ampliarse, entre otras obras, en: SALAZAR y CASTRO, Luis: Historia genealógica de la casa de Lara, Madrid, 1696, t. III, libro 16, pp. 209 y ss.; Crónicas de los Reyes de Castilla, Madrid, 1953, t. II, p. 56; Doubleday, Simon R.: The Lara Family. Crown and Nobility in Medieval Spain, Cambridge (Mass.), 2001, p. 189. 
1.2. Blanca de Lara = Juan Manuel, muerto en 1348.

1.2.1.Fernando Manuel, muerto en 1350.

1.2.1.1. Blanca Manuel, muerta sin hijos.

1.2.2. Constanza Manuel $=$ Pedro I, rey de Portugal.

1.2.2.1. Fernando I, rey de Portugal.

1.2.3. Juana Manuel = Enrique II, rey de Castilla (1369-1379).

1.2.3.1. Juan I, rey de Castilla (1379-1390).

1.3. Margarita de Lara, monja en Caleruega, muerta sin hijos.

1.4. María de Lara o de la Cerda, llamada en Francia "Marie d'Espagne" =1 Carlos de Évreux, conde de Étampes, muerto en 1336, =2 Carlos II de Valois, llamado "el Magnánimo", conde de Alençon, muerto en 1346 (Crécy).

Como en seguida comprobaremos, buena parte de los personajes de este entorno familiar de la protagonista de nuestro estudio (destacada en negritas) desempeñan un papel interesante en la articulación de lazos efectivos o potenciales de continuidad dinástica en la transmisión de los señoríos de Lara y Vizcaya en los últimos tiempos del rey Pedro y primeros de la nueva monarquía de los Trastámara ${ }^{4}$.

\section{SUMARIO DE LOS HECHOS SEGÚN EL CANCILLER AYALA}

A continuación, para ilustrar los antecedentes y circunstancias directamente relacionados con la figura de Juana de Lara como heredera de los señoríos de Lara y Vizcaya, procedemos a enlazar el relato cronológicamente ordenado de los hechos, tal como se sigue de las crónicas de Ayala, fuente principal. En su lugar, insertamos también las indicaciones oportunas sobre las preguntas e hipótesis de trabajo que prosiguiendo nuestro estudio deseamos poner de relieve.

- Juan Núñez de Lara III fallece en 1350 (en Burgos, el 28 de noviembre); la herencia de Lara y Vizcaya recae en su hijo Nuño, menor de edad (cfr. Ayala, Cr.P., año 1, 1350, cap. 14).

- Entre 1350 y 1352, breve y atribulado periodo del menor Nuño como señor de Lara (citado en el Libro becerro de las behetrías) ${ }^{5}$ y de Vizcaya (Ayala, Cr.P., año 2, 1351, caps. 7-10).

- A mediados de 1352 el pequeño Nuño fallece y la herencia de Lara y Vizcaya recae en su hermana Juana de Lara. Inmediatamente, el rey Pedro toma a las dos hermanas, Juana e Isabel de Lara, bajo su custodia y retiene los derechos señoriales sobre Lara y Vizcaya (Ayala, Cr.P., año 2, 1351, cap. 10).

- En virtud de un compromiso establecido anteriormente, reinando Alfonso XI, que el rey Pedro decide ahora llevar a debida consumación, como medio de uncir a

${ }^{4}$ En particular, el canciller Pero LóPEZ DE AyAla explica varias veces las relaciones de los miembros más recientes de la relación que acabamos de resumir: Crónica del Rey Don Pedro (en adelante, Cr.P.), año 2, 1351, capítulo 10, y Crónica del Rey Don Enrique II (en adelante, Cr.E-II), año 8, 1373, cap. 10.

5 Doubleday, The Lara Family, pp. 113-118. 
Tello a los fines de su política (al tiempo que lo separaba de Enrique) ${ }^{6}$, en 1353 se verifica el enlace matrimonial de Juana de Lara con Tello. Tello se convierte, por matrimonio, en señor de Lara y de Vizcaya; los esposos parten a Vizcaya a apoderarse del señorío, que hasta entonces había quedado en manos del rey (Ayala, Cr.P., año 4,1353 , cap. 28).

- En junio de 1358 Tello cae en desgracia. Pedro I acude airadamente a Aguilar de Campoo, de donde Tello, avisado justo a tiempo, acababa de huir, y prende a su esposa Juana de Lara (Ayala, Cr.P., año 9, 1358, cap. 4).

- En el mismo mes, Juan, infante de Aragón, casado con Isabel de Lara, hermana de Juana, pretende obtener el señorío de Vizcaya, pero Pedro I estorba su pretensión y lo hace matar (Ayala, Cr.P., año 9, 1358, caps. 5 y 6).

- Como consecuencia directa de la operación para neutralizar al infante Juan de Aragón, el rey Pedro prende a su madre, la reina Leonor de Aragón, y a su esposa, Isabel de Lara, y las hace encarcelar en Castrojeriz (Ayala, Cr.P., año 9, 1358, cap. 7).

- En 1359, Juana de Lara muere en su prisión de Sevilla, supuestamente sin dejar sucesión.

Examinemos brevemente el pasaje de la Crónica en que Ayala da cuenta de este suceso (Ayala, Cr.P., año 10, 1359, cap. 9):

"Otrosí mandó el rey levar presa a Almodóvar del Río, un castillo muy fuerte que está cerca de Córdova, a doña Juana de Lara, mujer del conde don Tello, su hermano, la qual tenía presa después que el rey fuera a Aguilar de Campó por matar a don Tello, según dicho avemos; e dende a pocos días la mataron a la dicha doña Juana en Sevilla."

Ayala omite el detalle de que fuera Pedro I quien ordenara esa muerte, si bien todo está dispuesto de manera que el lector entienda que en efecto fue así. ¿Hay algo especial en ello? En cualquier caso, es taxativo en afirmar que ella murió, y más adelante recogerá sin contradecirla una afirmación según la cual la tal Juana no dejó descendencia ("Todos estos fijos e fijas de don Juan Núñez morieron sin dexar fijos herederos de sus cuerpos": Ayala, Cr.E-II, año 8, 1373, cap. 10). Pero la redacción del pasaje citado más arriba no hace imposible que su última frase ("e dende a pocos días... en Sevilla") pudiera haber sido una postilla o adición posterior a un texto previamente formado.

En la pluma de autores posteriores que dependen fundamentalmente de Ayala para la narración de este suceso, la adjudicación al rey Pedro de esta muerte resulta mucho más clara. Así, la indicación concreta de que a Juana de Lara se le dio muerte por orden del rey aparecerá explícitamente en los Anales de Zurita ("mandó luego matar [...] a doña Juana de Lara mujer de don Tello": libro 9, cap. 2177), y en la Historia de la casa de Lara de Salazar:

${ }^{6}$ Díaz Martín, Luis Vicente: "Don Tello, señor de Aguilar y de Vizcaya (1337-1370)”, Publicaciones de la Institución Tello Téllez de Meneses, 47 (1982) 267-335 [276].

${ }^{7}$ Zurita, Jerónimo: Anales de Aragón (ed. Á. Canellas), t. IV, Zaragoza, 1973, p. 371. 
"Nuestra doña Juana de Lara, que no pudo egecutar la fuga, padeció luego los efectos del enojo del Rey, porque siendo primero detenida en Aguilar, fue conducida el año siguiente al castillo de Almodóbar del Río junto a Córdova: y últimamente a Sevilla, donde por orden de aquel cruelísimo príncipe la dieron injusta muerte sin aver tenido alguna sucesión" (t. III, libro 17, cap. 13, p. 212).

- En 1361 muere en su prisión de Jerez de la Frontera, envenenada, Isabel de Lara, viuda del infante don Juan de Aragón (Ayala, Cr.P., año 12, 1361, cap. 4). De acuerdo con la afirmación recogida por Ayala, citada más arriba (Ayala, Cr.E-II, año 8, 1373, cap. 10), tampoco esta dama dejó sucesión.

- En 1366, el recién proclamado Enrique II concede Lara y Vizcaya a su hermano Tello. En el pasaje de la crónica en que Ayala da cuenta de este nombramiento, se afirma que Juana e Isabel de Lara estaban muertas, y que, en consecuencia, no quedaba heredero en la descendencia de Juan Núñez de Lara y de María de Haro (naturalmente, en ese punto la sucesión podría haber pasado a las herederas de las ramas colaterales, Juana Manuel y Marie d'Espagne, sobrina y hermana de Juan Núñez III, respectivamente).

"E mandó [Enrique II] a don Tello su hermano que se llamase conde de Vizcaya e de Lara e de Aguilar, e señor de Castañeda. E como quier que primeramente don Tello ante que saliese del regno tenía el señorío de Vizcaya e de Lara por razón de doña Juana su mujer, fija de don Juan Núñez, [...] pero agora quando el rey don Enrique entró en el regno, la dicha doña Juana mujer de don Tello era finada, ca la ficiera matar el rey don Pedro, según suso avemos contado, e así mesmo ficiera matar a doña Isabel su hermana de la dicha doña Juana, e non fincaba heredero que fuese fijo del dicho don Juan Núñez e de doña María, su mujer, que heredase a Lara e a Vizcaya; e por tanto diolas el rey don Enrique, que agora regnara, al dicho don Tello" (Ayala, Cr.P., año 17, 1366, cap. 7).

- Inmediatamente, tiene lugar el curioso episodio de la impostura de la "falsa Juana": Tello conduce desde Sevilla a Burgos, para las "Cortes" celebradas allí por su hermano Enrique en 1366, a cierta mujer a quien se presenta como su legítima esposa, recién salida de la prisión en que la pusiera el rey Pedro, pero al cabo de unos días Tello declara que en realidad no se trata de la verdadera Juana de Lara (Ayala, Cr.P., año 17, 1366, cap. 20). La interpretación de este suceso dista de ser sencilla y clara, razón que nos mueve a examinarlo más de cerca en el próximo apartado de nuestro estudio.

- 1369, Enrique II rey. Tello gobierna Vizcaya como conde, no como señor ${ }^{8}$.

${ }^{8}$ L. V. Díaz Martín explica así la razón de esta importante diferencia: "Aunque el gobierno del territorio vizcaino quedaba nuevamente a cargo de Tello, sin embargo había perdido la dignidad de Señor del mismo. Ello era debido a la muerte sin descendencia de su mujer, Juana de Lara, ordenada por Pedro I, así como la de su hermana Isabel, lo que motivaba que se extinguiera el linaje de los Lara a quienes había correspondido el Señorío. En consecuencia, y dado el carácter de Señor consorte con que Tello había gobernado, éste no podía trasmitir sus derechos a descendientes que vinieran como consecuencia de otro matrimonio" ("Don Tello, señor de Aguilar y de Vizcaya", p. 306). Sobre la distribución de frecuencia en el uso de los términos "señorío" y "condado" (y sus derivados) referidos a Vizcaya, cfr. GonzÁlez Echegaray, Carlos: "Vizcaya: ¿señorío o 
- En 1370, fallece Tello. Rumores de envenenamiento. Carencia de herederos legítimos. En su segundo testamento, del mismo 1370, Tello deja Vizcaya a su hermano el rey9. El señorío de Vizcaya pasa al heredero Juan (futuro Juan I de Castilla) a través de su madre Juana Manuel, sobrina de Juan Núñez de Lara III y prima de Juana de Lara (Ayala, Cr.E-II., año 5, 1370, cap. 6). Añade Ayala: "E dio el rey algunos logares que fueron de don Tello a otros caballeros". ¿Menciona Ayala, con característica y reticente discreción, a los bastardos de don Tello? Pues sabemos que Juan obtuvo Aguilar y Castañeda ${ }^{10}$, y Alfonso, la "tierra de la Reina"11. En cualquier caso, las mercedes enriqueñas en beneficio de estos bastardos de su hermano Tello en nada afectan a la sucesión de Vizcaya, pues sólo unos eventuales herederos legítimos de Tello y Juana podrían haber aspirado con garantías a ella - y éstos, al parecer, nunca los hubo.

- En 1373, reunidas las Cortes en Burgos, un mensajero de María de Lara o de la Cerda, llamada "Marie d'Espagne", viuda del conde de Étampes y del conde de Alençon, reclama en su nombre, ante Enrique II, el señorío de Vizcaya, por derecho de herencia. Enrique II lo detenta por su esposa Juana Manuel, prima de la última titular del mismo, Juana de Lara; de esa misma Juana de Lara, María de Lara era tía, y se decía con mejor derecho a la sucesión. Sin desconocer este derecho, Enrique II delibera en consejo y halla una respuesta honrosa - pero envenenada - que salva la situación, disuadiendo al parecer a Marie d'Espagne de proseguir su demanda (Ayala, Cr.E-II., año 8, 1373, caps. 10 y 11). Nuevamente, diferimos el análisis más por menudo de este episodio para su correspondiente apartado posterior.

\section{EL MISTERIO DE LA "FALSA JUANA" DE 1366}

Como acabamos de recordar, en 1366, en pleno, improvisado y apresurado proceso de construcción de la legitimidad del nuevo poder Trastámara, convocado por el recién proclamado Enrique II un ayuntamiento en Burgos pensado como primeras Cortes de su reinado, tuvo lugar el episodio controvertido y problemático de la invención, hallazgo o rescate de la supuesta Juana de Lara, víctima del rey don Pedro, quien fue conducida desde su prisión sevillana hasta Burgos, donde fue presentada como la legítima mujer de don Tello, y después de algún tiempo, que Ayala no precisa (si bien desea transmitir la idea de que fue un periodo muy breve, apenas unos

condado?", en Edad Media y señoríos: el señorío de Vizcaya (Simposio de la Real Sociedad Vascongada de los Amigos del País, Bilbao, marzo 1971), Bilbao, 1972, pp. 207-214. Precisiones sobre la historia de Vizcaya como condado se incluyen en el resumen de García-Gallo, Alfonso: "El régimen público del señorío de Vizcaya en la Edad Media", en Vizcaya en la Edad Media (Congreso de Estudios Históricos, Bilbao, diciembre 1984), San Sebastián, 1986, pp. 85-98.

${ }^{9}$ El texto de este segundo testamento fue publicado por Díaz Martín, "Don Tello, señor de Aguilar y de Vizcaya", pp. 332-333 [332, la manda dejando Vizcaya a Enrique II].

10 1371, febrero 18, Sevilla: Real Academia de la Historia (Madrid), Colección Salazar, M-2, fols. 296r-299v.

${ }^{11}$ 1371, febrero 18, Sevilla: RAH, Col. Salazar, M-14, fols. 137r-140r. 
días), rechazada como impostora. El pasaje de la crónica que recoge estos sucesos, a pesar de las precauciones reiteradas de Ayala, comunica cierta impresión de ambigüedad, de manera que no es irrazonable postular que, en realidad, la verdad sobre el hecho dista de quedar definitivamente aclarada:

"fue dicho que una dueña que estaba en Sevilla presa por mandado del rey don Pedro se llamaba doña Juana de Lara, mujer del conde don Tello, e el rey fízola traer a Burgos. E como quier que fue, don Tello dixo luego que era su mujer, e levóla a su casa; empero decía en su secreto, que lo facía por aver algund título a Lara e Vizcaya, recelando que aquella mujer se fuese a la partida del rey don Pedro, e que los vizcaynos, como son omes muy a su voluntad, tomasen con ella alguna imaginación, porque don Tello perdiese el señorío de Lara e de Vizcaya. E aunque don Tello era cierto que aquella non era doña Juana de Lara, algunos días tóvola así por mujer: empero después lo negó públicamente, e fue fallado que non era ella, ca el rey don Pedro ficiera matar en Sevilla a la dicha doña Juana, mujer de don Tello gran tiempo avía: e aun después don Martín López de Córdoba quando fue preso en Carmona así lo confesó, e dixo que era muerta doña Juana de Lara, e mostró el logar do estaba soterrada" (Ayala, Cr.P., año 17, 1366, cap. 20).

De hecho, lo extraño del episodio y la impresión de soterrada ambigüedad a la que acabamos de referirnos han inducido sospechas en algunos autores. Simon R. Doubleday no está lejos de creer que la Juana de Lara que fue conducida en 1366 de Sevilla a Burgos era efectivamente la verdadera, la legítima esposa de Tello, aún viva $^{12}$. Las dudas de este historiador, y las nuestras propias, nos invitan a considerar, siquiera como hipótesis, la alternativa de que Juana de Lara hubiera sobrevivido a su prisión y en 1366 fuera verdaderamente llevada a Burgos.

En principio, una operación de tanto significado y potencial repercusión propagandística para la causa del Trastámara como rescatar a la titular del señorío de Vizcaya, últimamente detentado por el rey Pedro, de la prisión, y conducirla a Burgos, donde se celebraban las emblemáticas primeras Cortes del reinado de Enrique, sin duda resultaba altamente atractiva, pero también debería haber sido meditada a conciencia, tomando en consideración sus posibles consecuencias: suponía, concretamente, adquirir y poner en escena, en un momento crucial, otra fuente de legitimidad como sustento del nuevo poder emergente, esta vez referida a Vizcaya. El mismo poder Trastámara podría haber sido engañado inicialmente sobre la identidad de aquella mujer, como luego declararon, pero ¿cómo creer que antes de conducirla de Sevilla a Burgos no se hubiera verificado cuidadosamente quién era en realidad? Sin embargo, al cabo de un tiempo, y tras considerar más detenidamente el asunto, se escogió presentarla como una impostora, y conferir Vizcaya a Tello, no como señorío (vinculado a la legitimidad de los Lara) sino como condado (por concesión especial o mandatio del nuevo rey emergente Enrique). Si la de 1366 era la verdadera Juana, ¿cuál habría

12 Doubleday, The Lara Family, p. 121: "But given the pro-Trastámara agenda of this chronicle, is surely conceivable that this was the real Juana. King Enrique would have been desperate to retain Lara and Vizcaya; and while his marriage to Juana Manuel gave him some claim to these lordships, his claim was inferior to Don Tello's. Any unscheduled appearance by the original heiress would have been the last straw, and certainly there was persistent tension between Enrique and Don Tello over the two lordships." 
sido la razón de debelarla ahora como impostora? ¿Era o podía ser Juana de Lara afín a la causa del rey Pedro? ${ }^{13}$ ¿Se desconfiaba que pudiera caer en manos de los petristas y que de esa manera Vizcaya pudiera escapársele a Tello - y a Enrique? A priori, parece poco creíble que una vez en Burgos, en manos de Enrique y Tello, esta dama pudiera escapárseles para pasarse al bando petrista.

Si esta mujer no era la verdadera Juana de Lara, el crédito del nuevo poder Trastámara emergente podía esperar un seguro quebranto como resultado del repentino cambio de criterio sobre su identidad. Si creían que era una impostora, una vez lograron que fuera aceptada como la verdadera Juana de Lara - y cabe creer que de ello obtenían un provecho, pues de lo contrario no les habría merecido la pena poner en marcha la operación -, ¿qué pudo inducir a Enrique y Tello a darle la vuelta de nuevo a toda la historia para declarar ahora que se trataba de una impostora aquella a quien acababan de presentar y hacer pasar como la legítima Juana, aun a sabiendas de que la brusquedad de este último viraje por fuerza habría de actuar en contra de su credibilidad, cualidad de la que nunca anda sobrado cualquier poder emergente?

Como se aprecia, la disyuntiva en este punto es muy clara: la Juana de Lara de 1366 era la verdadera, o no lo era: detenidamente consideradas, es difícil decidir cuál de ambas hipótesis resulta más arriesgada o comprometida.

Por supuesto, la principal desventaja de la hipótesis según la cual la Juana de Lara de 1366 era la verdadera es que choca con el testimonio taxativo del canciller Ayala, un cronista esencialmente veraz, al que no imaginamos mintiendo reiteradamente, con todas las letras, sobre este asunto, cada vez que da cuenta del mismo. Y sin embargo, hay un camino seguro para dudar de la afirmación de Ayala sobre la muerte de Juana de Lara en 1359, sin comprometer su honradez como cronista: en este punto, su relato se apoya, sobre todo, en el testimonio del que fuera último maestre de $\mathrm{Ca}$ latrava bajo el rey Pedro, Martín López de Córdoba ${ }^{14}$, obtenido mientras éste estuvo preso en Carmona, luego de rendir la fortaleza a Enrique II, tras pertinaz resistencia como uno de los últimos baluartes en armas de la causa petrista. Fue él quien declaró, aún en Carmona, que Juana de Lara murió en 1359, e incluso indicó el lugar preciso donde fue enterrada; posteriormente, Enrique II dispuso que los restos de aquella dama fueran exhumados para procurarles un enterramiento más digno. Este testimonio debió ser determinante para el hallazgo, exhumación e identificación de esos restos, porque Ayala lo cita como único argumento de autoridad aducido expresamente. Pues bien, ¿y si esta confesión le fue arrancada a Martín López mediante tormento? Desde luego, el mismo relato de Ayala, quien en dos ocasiones declara que, antes y después de que cayera en sus manos, Enrique II estaba "muy sañudo" de Martín López ("ovo grand saña e grand sentimiento de don Martín López": Ayala, Cr.E-II, año 6, 1371, cap. 1; "por la saña que avía dél”: ibidem, cap. 2), autoriza a suponerlo. De

${ }^{13}$ En este punto quizás sea significativo recordar que en 1356, en su "scripto de condiciones", los procuradores vizcaínos reconocieron a Juana como señora, pero sólo en tanto se mantuviera en el servicio del rey (LABAYRu GoicoecheA, Estanislao Jaime de: Historia general del señorio de Vizcaya, Bilbao, 1968-1971, t. II, pp. 374-376 (facsímil de la ed. orig. de Bilbao, 1895-1903).

14 Díaz Martín, L. V.: "La elección de Martín López de Córdoba como maestre de Calatrava", en Homenaje a fray J. Pérez de Urbel, Silos, 1976, t. I, pp. 423-432; Molina Molina, Ángel Luis: "Don Martín López de Córdoba, maestre de las órdenes de Alcántara y Calatrava y adelantado mayor del reino de Murcia", Miscelánea Medieval Murciana, 4 (1978) 87-105. 
Enrique II, a cuenta de la captura de este Martín López, se censura en el propio relato de Ayala la falta de caballerosidad en que incurrió al matarlo luego de haber logrado su rendición bajo la promesa de ofrecerle seguridad personal. ¿Es impensable que la cólera de Enrique se abatiera sobre Martín López en forma de tormento tras su captura? ¿Y cuando éste declaró sobre la muerte y paradero del cuerpo de Juana de Lara, se trataba, tal vez, de un testimonio fabricado por la tortura, y orientado en la dirección que deseaba el poder Trastámara? Interrogante sugestivo, pero en el fondo incomprobable.

¿Qué ganaba Enrique II en ocultar que la verdadera Juana de Lara aún vivía, si esto último hubiera sido cierto? En primer lugar, si su hermano se apoderaba de Vizcaya, no en virtud del derecho hereditario de su esposa legítima, esto es, no como depositario de una legitimidad propia, sino meramente como conde, esto es, como beneficiario de una concesión graciosa y revocable del soberano, a éste siempre le resultaría más sencillo retirarle a Tello el gobierno de Vizcaya cuando quisiera, y desde luego existen razones fundadas para suponer que Enrique II no se fiaba plenamente de Tello. En segundo lugar, si la existencia de Juana de Lara se desconocía, y Tello no volvía a cohabitar con ella, se impedía que los esposos pudieran engendrar la descendencia legítima que hasta entonces les había faltado, y de esta suerte, tras la muerte de Tello, Enrique II hallaría vía libre para la anexión de Vizcaya a la corona, a través de los derechos sucesorios sobre el señorío de su esposa Juana Manuel. A lo que podríamos añadir (en base a lo que expondremos en la última parte de nuestro estudio): previsoramente, Enrique II se reservaba un "as en la manga", en caso de que alguna vez fuera necesario emplearlo frente a una eventual reclamación, de momento poco previsible, de Marie d'Espagne, dama célebre, a la que el mismo Enrique había tratado en persona, y cuyo parentesco con los Lara y con la misma familia real nueva - tía de la reina Juana Manuel - no podía pasarle inadvertido al Trastámara.

\section{1373: DOS CANDIDATAS RECLAMAN LA SUCESIÓN DE VIZCAYA}

Como recoge Ayala y ya hemos mencionado en nuestro anterior relato sucinto de hechos, en 1373, Enrique II hubo de hacer frente a una reclamación por el señorío de Vizcaya presentada por María de Lara, Marie d'Espagne, condesa viuda de Alençon, quien como tía de la última señora de la línea de los Lara se consideraba con mejor derecho a la sucesión que la esposa del monarca, la reina doña Juana Manuel, prima de la misma Juana de Lara (Ayala, Cr.E-II., año 8, 1373, cap. 10).

La versión llamada Abreviada de la misma crónica despacha el asunto en muy breves trazos, sin recoger los argumentos de la reclamante ni representar la deliberación del consejo en torno al rey; aporta en cambio, como detalle suplementario, el nombre del emisario de Marie d'Espagne llegado ante Enrique II e incluso se detiene a describir su persona, cuya memoria sin duda estaba fresca aún en el vívido recuerdo del cronista:

“Este año dicho doña María de Lara, hermana de don Juan Núñez de Lara, e condesa de Alanzon, que era en Francia, envió al Rey Don Enrique un caballero de Bretaña, 
que decían Mosén Thomás de Peñahedit, e era muy buen caballero, ca fuera uno de los treinta bretones que pelearan con los treinta ingleses, e los vencieran, e era ya viejo, e cojo de la pierna de feridas que ovo; e llegó al Rey en Burgos, e diole sus cartas de creencia que traía de la condesa: e por la creencia diole [el Rey] una escritura, que decía que non quería darle a Vizcaya, que non la avía porqué aver otro" (Ayala, Cr.EII., texto de la vers. Abreviada, recogido como adición al año 8, 1373, cap. 10 de la edición de la RAH, Madrid, 1953, t. II, p. 18, nota 3).

Tal vez en un segundo momento, luego de consignar en la primera versión de la obra los datos de que disponía, Ayala recibió o pudo confirmar más detallada información de primera mano sobre esa deliberación, y decidió incluirla en su crónica, especialmente por entender que ilustra de manera expresiva y memorable el buen criterio, el "talento práctico" de Enrique II, cuando tras oír la deliberación de sus consejeros dio con la respuesta justa que la situación demandaba, y que al punto fue convenientemente alabada y puesta en práctica ${ }^{15}$.

Por lo demás, como se percibe, la argumentación recogida en el escrito que el emisario de María de Lara leyó ante el monarca no era en modo alguno irrazonable: teniendo en cuenta los derechos que concurrían en la persona de la condesa de Alençon en virtud de su estrecho parentesco con la última línea que ostentó el señorío de Vizcaya, así como rememorando algunos lances especialmente escogidos de la sucesión en la misma corona castellana, puede llegarse a la conclusión de que la causa de esta demandante no era, en principio, extravagante ni desesperada ${ }^{16}$.

De hecho, cuando, oído el emisario de la condesa viuda de Alençon, Enrique II reunió el consejo para acordar una respuesta adecuada a su demanda, parece que hubo cierta agitación y división de opiniones en torno al monarca: unos aconsejaban someter el pleito a los oidores de la Audiencia (esto es, darle una tramitación ordinaria); otros consideraban "que estas dos casas de Lara e de Vizcaya son los dos mayores señoríos que en el regno avía, e que era fuerte cosa ponerlas en juicio e pleyto [...] que non sabían los omes lo que ella [la condesa] podría provar"(Ayala, Cr.E-II, año 8,1373 , cap. 11). ¿Creían acaso estos últimos que la condesa de Alençon tenía razón en su demanda y podría llegar a acreditarlo de manera tan paladina que ni siquiera los oidores de la Audiencia real de Castilla pudieran desconocer sus mejores derechos a la herencia sobre los de la reina Juana Manuel?

En cualquier caso, Enrique II zanjó la polémica descubriendo su intención de esquivar la demanda con una propuesta honrosa pero envenenada, que a la postre salvó la situación: previendo que los hijos de María de Lara, muy consolidadamente establecidos en el reino de Francia, rehusarían venir a fijar su residencia en Castilla,

15 "Hay una estructuración profunda de la historia que Ayala armó al redactar la Prim. [Primitiva = Abreviada] y respetó en la reelaboración de la Vulg. [Vulgata = Vulgar]; pero los recursos que emplea en la redacción de la Vulg. (amplificación, aclaraciones, reordenamiento) revulsionan de tal modo el plano del discurso que determinan la creación de un nuevo relato. En esa renovación del plano del discurso radica la clave de la maestría cronística del viejo Canciller y es allí donde puede rastrearse la intencionalidad que caracteriza la segunda versión": ORDUNA, G.: "El cotejo de las versiones Vulgata y Primitiva como recurso para la fijación del texto cronístico del canciller Ayala. (Ensayo de un método)", Incipit, 8 (1988) 1-24 [14].

${ }^{16}$ Estepa Díez, Carlos: "Doña Juana Núñez y el señorío de los Lara”, e-Spania, 1 (2006): http://e-spania. revues.org/315, se concentra en analizar el papel de las mujeres en la transmisión de derechos sucesorios en la casa de Lara y dedica cierta atención a los argumentos de la condesa viuda de Alençon. 
estableció precisamente ese requisito como necesario para proceder a reconocerles los supuestos derechos a la sucesión de Lara y Vizcaya. Oída la respuesta del rey, sólo formalmente satisfactoria, el emisario regresó a Francia, y Ayala ya no registra en sus crónicas nuevos pasos dados por la condesa de Alençon al respecto.

Sin embargo, contando con información posterior, Salazar afirmó en su Historia de la casa de Lara, a cuenta de este momento, que dicho emisario en efecto "se bolvió a Francia: sin que despues desto sepamos que aquella princesa [María de Lara] hiciese nueva diligencia, hasta que su visnieto Juan II, duque de Alençón, la repitió el año 1463, como diremos en su lugar" (Salazar, Hist. Lara, t. III, libro 17, cap. 18, p. 236). Anticipa así el nuevo planteamiento del que, en esencia, era el mismo pleito, reactivado casi un siglo más tarde por un descendiente de la condesa María de Lara, concretamente el duque de Alençon Juan II, quien al parecer, con ocasión de la histórica entrevista del Bidasoa entre Enrique IV y Luis XI, aprovechó para volver a insistir en la demanda de su antepasada:

“suscitó este príncipe [Juan II de Alençon] la antigua pretensión de los Señoríos de Lara, y de Vizcaya [...] y pasando con el Rey Luis XI a las vistas que mas allá del río Vidasoa tuvo el año 1463 con el Rey Don Enrique IV, representó allí sus derechos a este príncipe, y obligándose a rendirle el homenage a que era obligado, pidió la posesión de aquellos estados, como verdadero sucesor de la princesa doña María de Lara su visabuela [...]. Toda esta representación incluyó el duque en un instrumento, que autenticó un notario apostólico en Bayona a 14 de mayo de 1463, y refiere M. Gilles Bry que, aviéndola recivido el Rey Don Enrique IV, no quiso dar otra respuesta que la de estar ocupado en mayores negocios. Pero en las adicciones de la Historia de Perche copia un parecer dado a su Magestad por algún ministro suyo a quien cometió este caso, en el qual, repitiendo la instancia del duque, y confesando el derecho de su visabuela, resuelve que su Magestad debía admitirle a la fe y homenage que se ofrecía, y darle la investidura de aquellos estados. En las historias castellanas falta enteramente la memoria de esta solicitud del duque de Alençón: y lo cierto es, que si la hizo tan eficaz como M. Gilles Bry refiere, la gravedad e importancia del negocio, ya olvidado por casi un siglo, y la falta de contestación, interpusieron tales embaraços, que ni el Rey quiso entrar en él, ni los duques de Alençón han buelto a suscitarle: o conociendo débil su derecho, o estimando insuperable la dificultad de separar de la Corona dos tan grandes estados, que por la representación de la primera línea recayeron indubitablemente en ella" (Salazar, Hist. Lara, t. III, libro 17, cap. 18, pp. 240-241).

Pero regresando al año 1373 y al razonamiento que aquel emisario bretón presentó ante Enrique II en nombre de la condesa María (pues la nueva reclamación de 1463 no tiene otro fundamento), conviene que dirijamos nuestra atención hacia cierto detalle crucial, en que la misma demandante hacía referencia expresa, y prolija, a la cuestión, vital para el éxito de su pretensión, de si Juana de Lara, la que fuera esposa de don Tello, estaba viva, o no. Naturalmente, su argumentación se dirigía a demostrar que Juana de Lara había muerto, pues estando ésta viva, sólo a ella le habría pertenecido la herencia legítima de Lara y Vizcaya, sin que pudieran alegarse otros derechos sucesorios como justificación para su apropiación por la reina Juana Manuel, ni por la misma condesa de Alençon. 
Concretamente, María de Lara alegó en esta razón:

\begin{abstract}
"Otrosí, vos señor rey don Enrique, quando estábades en París, que érades conde, e érades y con el rey don Juan de Francia, dixistes a la dicha doña María condesa de Alanzón, mi señora, cómo sus sobrinas fijas de don Juan Núñez su hermano [...] eran muertas, e como vos sabíades muy bien que ella debía ser heredera de Vizcaya e de Lara, e que fiávades en Dios que vos le ayudaríades a cobrar las dichas tierras. E como quier que después algunas personas oviesen dicho que la dicha doña Juana de Lara, su sobrina, mujer que fue de don Tello vuestro hermano, era viva, esto non es de creer, ca vos el señor rey de Castilla e todos los de la tierra saben ciertamente que la dicha doña Juana era muerta, ca la ficiera matar el rey don Pedro en Sevilla, e después fue fallada su sepultura cerca la iglesia de Sant Miguel de Sevilla, segund a mí es dicho por omes de creer. E aun el conde don Tello confesó e dixo al tiempo de su muerte, que aquella que se decía doña Juana de Lara non era su mujer, pero que lo consintiera por segurar la tierra de Vizcaya. E vos, señor rey de Castilla, sabedes muy bien que esta dicha doña Juana está enterrada en Sevilla, e que vos la mandastes desenterrar e tirar del logar donde estaba, e poner en otro logar mejor que non era aquél" (Ayala, Cr.E-II, año 8, 1373, cap. 10).
\end{abstract}

Cuando María de Lara, condesa de Alençon, descarta la idea (o el rumor) de que su sobrina Juana de Lara hubiera sobrevivido, no se está refiriendo tanto a los sucesos de 1366, que a las alturas de 1373 ya no deberían representar para ella amenaza alguna si, como ella recuerda, el mismo Tello reconoció que realmente aquella mujer no era la suya, no era la verdadera Juana: todo el asunto aquel se había resuelto ya, por fuerza había de ser "agua pasada", y no se comprende que mereciera atención, en términos tan detallados, por parte de la condesa de Alençon para fundar su propia demanda. El hecho de que esta dama juzgara necesario recordar, después de todo, a Enrique II que él mismo estando en París le había informado de la muerte de Juana, y que tras los sucesos de 1366 así lo volvió a remachar disponiendo que se le procurara un enterramiento mejor, sugiere una preocupación bien concreta por descartar la posibilidad de que Juana siguiera con vida, como un empeño aún acuciante, relacionado con un asunto más reciente, algo de actualidad.

Probablemente, cuando la condesa de Alençon decidía los términos de la demanda que se proponía hacer presentar ante Enrique II, ya tenía conocimiento de la reclamación por la sucesión de Vizcaya que en el mismo 1373 se había presentado ante la Curia pontificia, en nombre de una Juana de Lara (verdadera o falsa), y por ello se refirió en términos concretos a la pretensión que "algunas personas" tenían de que Juana de Lara había sobrevivido a su prisión y aún podía reclamar para sí la herencia de Lara y Vizcaya, como una amenaza actual sobre sus propias pretensiones, y por consiguiente un asunto que era preciso aclarar, dedicándole toda la atención y todo el espacio que hemos visto le concede en su escrito.

Y es que, en efecto, en 1373 una que decía llamarse Juana Núñez y ser mujer noble, hija de Juan Núñez (de Lara) y María (de Haro), "condesa de Vizcaya", nacida en la diócesis de Calahorra, viuda de Tello - habiendo sido con él condesa de Vizcaya -, actualmente casada con Pedro de Béarn, llegó hasta el papa Gregorio XI y logró que la cancillería pontificia de Aviñón expidiera sendas cartas destinadas al rey Enrique II, a la reina Juana Manuel, y al legado pontificio Guido de Boulogne (que por 
entonces se ocupaba de la paz entre los monarcas peninsulares cristianos, entre otros asuntos comisionados por el pontífice): en dichas cartas, se solicitaba que el asunto se averiguase, y que, si se hallase que la reclamante tuviera razón ("si uera sunt"), se le restituyese el condado de Vizcaya ${ }^{17}$.

Condado, y no señorío. ¿Por qué? ¿Pura formalidad de la redacción latina propia de la documentación emanada de la cancillería pontificia? ¿O se hace referencia, concretamente, como más directo precedente histórico de la trayectoria de Vizcaya antes de su plena integración al señorío directo de la corona castellana, al periodo de tiempo en que Tello tuvo Vizcaya como condado de Enrique II hasta su muerte en 1370 ? $^{18}$

Nuevamente, nos hallamos ante la difícil alternativa de considerar si esta Juana Núñez que en 1373 hizo llegar a la Curia de Aviñón su propia reclamación sobre Vizcaya era la verdadera o no. Si optamos por considerar que nos hallamos ante una impostora, aún podemos elaborar más de una hipótesis para explicar su reclamación. Pudo, desde luego, tratarse de una especie de "Anastasia del siglo XIV" (en recuerdo - no exento de ironía - de la leyenda del siglo XX sobre la gran duquesa rusa que supuestamente sobrevivió a la matanza de Ekaterimburgo): una aventurera, en suma, tal vez la misma que en el pasado había representado el papel de Juana de Lara para Tello mientras pareció necesario, y que ahora, casada con un francés, probaba otra vez fortuna aspirando a la herencia de Vizcaya por su cuenta y riesgo. O quizás podría verse en ella una hechura del mismo Enrique II, decidido a emplear cualquier triquiñuela, con tal de impedir que la herencia de Lara y Vizcaya pudiera recaer en la poderosa casa de los condes de Alençon: una mujer, la misma que fue utilizada por Tello en 1366, u otra distinta, que ahora es movida por Enrique II como maniobra de distracción, para confundir, enredar y dilatar el pleito todo lo posible y, a la postre, disuadir a Marie d'Espagne de llevar adelante su propia reclamación.

Por supuesto, resulta en principio extraño, incluso duro de creer, que en la cancillería pontificia de Aviñón los sofisticados servicios administrativos, diplomáticos y de información de la Santa Sede se avinieran a prestar oídos a la reclamación de una impostora que, como tal, debería haber sido sencillo desenmascarar, y se llegara así al fuerte compromiso de expedir sendas cartas pontificias destinadas al rey de Castilla, a la reina, y al legado cardenal Guido (al menos, la redacción de la cancillería pontificia introduce ciertas fórmulas de cautela: "si esas cosas son ciertas": "si uera sunt", "si [Vizcaya] le pertenece a ella": "si ad eam pertinet") ${ }^{19}$. Es la principal desventaja, tal vez la única, de esta "hipótesis A": que la Juana citada en los documentos pontificios de 1373 fuera una impostora.

En cuanto a la "hipótesis B": que esa misma mujer fuera la verdadera Juana de Lara, nos remite a cuanto ya expusimos sobre la fiabilidad de Ayala como cronista y

17 Véase el texto de estos tres documentos en nuestro apéndice documental.

18 Vid. supra, nota 8 de este trabajo.

19 Sobre la estructura y funcionamiento de la cancillería apostólica, incluyendo precisiones sobre los procuradores que en ella presentaban las súplicas y recibían las bulas destinadas a sus clientes, cfr. BARBICHE, Bernard: "Le personnel de la chancellerie pontificale aux XIIIe et XIVe siècles", en Prosopographie et genèse de l'État moderne. (Actes de la table ronde CNRS octubre 1984) (F. AuTRAND, ed.), París, 1986, pp. 117-130 [120-121]. 
su dependencia del testimonio - probablemente obtenido mediante tormento - de un petrista irredento, Martín López de Córdoba.

Por lo demás, al lado de los documentos pontificios que acabamos de citar, existen algunos otros testimonios de la pervivencia de una línea residual de los Lara vinculada a la herencia de la hermana de Juana, Isabel, enlazada con una rama de los Béarn (la del bastardo Pedro, medio hermano del conde Gastón III Febo), que asimismo mantuvo una reivindicación propia sobre el señorío de Vizcaya. Dentro de la historiografía española, es Salazar quien, en su obra general sobre la casa de Lara, recoge y menciona estos indicios, como referidos a la supuesta descendencia legítima que Isabel de Lara y su esposo el infante Juan de Aragón habrían tenido tiempo de engendrar antes de sucumbir a la ira del rey Pedro:

"Nuestras historias afirman no aver dejado el infante y doña Isabel sucesión alguna: pero parece que tuvieron dos hijas, llamadas doña Florencia y doña Isabel. Así lo vimos en una memoria que el licenciado Juan Díaz de Fuenmayor, del consejo y cámara de Felipe II, dejó escrita de una carta de la reyna doña Juana Manuel, fecha con consentimiento del conde don Enrique su marido, en Monblanc, a 3 de noviembre de la era 1403, que es año del Señor 1365, en que da a Mari Gonçález de Mendoza, su camarera, todos los derechos que tenía en la vicaría de Atazano, por el señalado servicio que la hizo en acatar y guardar a doña Florencia y doña Isabel de la Cerda, hijas del infante don Juan y de doña Isabel su prima, y llevarlas a Bayona. Lo qual confirmó el conde don Enrique, llamándose rey, en Calahorra, a 22 de mayo del año 1366 a Miguel López de Lezcano, su vasallo, y Mari Gonçález de Mendoza, su muger. Don Diego Ortiz de Zúñiga, en la tabla genealógica de la casa de la Cerda que está al principio de sus Anales de Sevilla, conoció estas dos princesas: y añade que doña Florencia casó con don Pedro de Bearne, y ambos pretendieron el señorío de Vizcaya, y procrearon a don Pedro y doña Adriana de Bearne. Pero esta novedad, opuesta a todo el curso de los historiadores, necesitava de grande prueba, y así no llegando a dudar que el infante y doña Isabel de Lara tuvieron aquellas dos hijas, entendemos que ambas fallecieron en tierna edad" (Salazar, Hist. Lara, t. III, libro 17, cap. 14, p. 215).

Bien que con reticencia, Salazar se hace eco, en este pasaje, de la posibilidad de que Isabel de Lara y el infante Juan de Aragón hubieran tenido, después de todo, descendencia. Y de hecho, en un pasaje anterior, al referirse al ardid de Tello en 1366, Salazar desliza una frase significativa, que aquí marcamos en cursivas:

"Y aunque en fuerça desta gracia entró este príncipe [Don Tello] en la posesión de aquellas casas, como conocía que no tenía título bastante para gozarlas, pues no podía el Rey disponer dellas en perjuicio de aquellos a quien por el derecho de la sangre pertenecían, fingió luego que doña Juana su muger era viva, y recivió en su lugar otra muger, que en el semblante tenía alguna similitud con aquella princesa. Pero la verdad del hecho, o la propia inconstancia de su genio, le hicieron confesar presto la suposición" (Hist. Lara, t. III, libro 17, cap. 13, p. 212).

¿Por qué escribe esto Salazar? Porque conoce los derechos a la sucesión de la casa de Lara que concurrían en Marie d'Espagne, y tal vez influido asimismo por la 
noticia, que luego maneja, sobre la descendencia de Isabel de Lara y el infante Juan de Aragón.

En cualquier caso, salta a la vista que Salazar no había leído a Froissart. El celebérrimo autor francés dedica un capítulo entero del libro tercero de sus famosas Crónicas a la curiosa historia de Pedro (Pierre) de Béarn, medio hermano bastardo del conde Gastón III Febo de Foix-Béarn ${ }^{20}$. El testimonio recogido por Froissart resulta un tanto indirecto, pero parece digno de confianza, especialmente porque la notoriedad del personaje le habría disuadido ceder al espíritu de fabulación ${ }^{21}$. Tal como le refirió cierto escudero, Pierre de Béarn se hallaba casado con "la contesse Florence de Bisquaie", de la que tenía dos hijos de corta edad, Pierre y Adrianne. De acuerdo con el relato recogido por Froissart, esta Florencia era hija de cierto conde de Vizcaya, primo del rey Pedro de Castilla, quien lo hizo matar ${ }^{22}$. También se añade que esta Florencia fue dama de la cámara de la reina de Castilla Blanca de Borbón, y que cuando dicha reina murió, el rey Pedro tuvo interés en hacer desaparecer a Florencia, a fin de que no pudiera testificar sobre dicha muerte ${ }^{23}$. De manera que Florencia huyó al país de Béarn, donde fue gentilmente acogida por el conde Gastón Febo, el cual le dio cuanto necesitaba y la casó con su medio hermano Pierre, con quien aún mantenía una excelente relación ${ }^{24}$. Más tarde, Pierre, tras cazar en los bosques vizcaínos un

${ }^{20}$ Froissart, Jean: Chroniques. Livre III (du voyage en Béarn à la campagne de Gascogne) et Livre IV (années 1389-1400), (eds. P. Ainsworth - A. Varvaro), París, 2004, pp. 189-195. Entre los estudios sobre el viaje de Froissart al Béarn: LALANDE, Denis: "Un grand reporter médiéval dans le Midi: Froissart en Béarn”, Midi. Revue de sciences humaines et de littérature de la France du Sud, 2 (1987) 39-47; Diller, George T.: "Froissart's 1389 Travel to Béarn. A Voyage Narration to the Center of the Chronique", en Froissart across the Genres, Gainesville, 1998, pp. 50-60. Sobre Pierre de Béarn y su actividad al servicio de su medio hermano Gastón Febo, cfr. Tucoo-Chala, Pierre: Gaston Fébus et la vicomté de Béarn (1343-1391), Burdeos, 1959, pp. 124 , nota 27 , y 128 (nota 47).

${ }^{21}$ En este respecto, se ha señalado que a partir del libro III, las Chroniques de Froissart se vuelven más personales, más literarias: más lo que entenderíamos por unas "memorias". "On voit alors les Chroniques combiner au temps de l'histoire un temps proprement poétique, le temps du récit et le temps de la mémoire"; "l'on passe des chroniques aux mémoires. C'est de cette façon que le présent de la vie de Froissart et les souvenirs personnels de ce qui'il a vécu l'emportent sur la mémoire objective des événements ou du moins en commandent la transmission": ZINK, Michel: Froissart et le temps, París, 1998, pp. 18, 78. Refiriéndose concretamente a los asuntos relacionados con el reinado de Pedro I de Castilla, J V. Díaz MarTín expresa reservas sobre la fiabilidad de Froissart: "incorpora datos que no ha comprobado, lo que le convierte en vehículo para las más burdas patrañas y campañas propagandísticas" (Pedro I el Cruel, op. cit., p. 19). Acerca de la relación de las Chroniques con el dominio de la ficción: HARF-LANCNER, Laurence: "Chronique et roman: les contes fantastiques de Froissart”, en Autour du roman. Études présentées à Nicole Cazauran, París, 1990, pp. 49-65.

22 "Et fu son pere conte de Bisquaie, et estoit cousin germain du roy Dampietre qui fu si cruel, le quel roys Dampietre le fist mourir, et vouloit aussi avoir par devers lui ceste dame pour la emprisonner, et saisi toute sa terre": Froissart, Chroniques, livres III-IV, p. 191.

23 "Dame, sauvez vous, car se le roy Dampietre vous tient ils vous fera mourir ou mettra en prison, tant est fort courrouciez sur vous, pour tant que vous devez avoir dit et tesmoignié que il fist mourir en son lit la royne sa femme [...]. Vous en estes mieulx creue que nulle autre, car vous estiez de sa chambre": Idem.

24 "Pour celle doubte la contesse Florence de Bisquaie se parti de son pays à petite compaignie [...], et se mist ou païs des Bascles et passa parmi, et fist tant à grant paine que elle vint ceans devers mon seigneur, et lui compta toute son aventure. Le conte [...] en ot pitié et la retint [...], et la pourvey de ce que il lui appartenoit. Messire Pierre de Berne son frere estoit lors jeune chevalier et [...] grandement en la grace du conte. Si fist le mariage de celle dame et de lui ": Idem. 
enorme oso al que mató por su propia mano, con gran temeridad, contrajo un extraño sonambulismo: la violenta impresión recibida, al parecer, le hacía levantarse en sueños y no hallaba descanso hasta que encontraba sus armas y se revestía con ellas, lo cual causaba turbación e incidentes desagradables entre la servidumbre ${ }^{25}$. Debido a este cambio en su salud mental, su esposa Florencia lo abandonó y pasó a Castilla, so pretexto de peregrinar a Santiago, llevando consigo sus bienes de valor y a los dos hijos del matrimonio ${ }^{26}$. En Castilla, fue bien recibida por Juan I, a quien en el relato recogido por Froissart se identifica como "primo" de esta Florencia (y en efecto, Isabel de Lara, la supuesta madre de Florencia, y Juana Manuel, la madre de Juan I de Castilla, eran primas hermanas).

Nada entre los detalles aportados por la narración de Froissart está desacordado: antes parece que todo casa razonablemente. Como sabemos, el infante Juan de Aragón, que era primo del rey Pedro de Castilla, estaba casado con Isabel de Lara, aspiró a Vizcaya y murió por ello en 1358. Isabel y Florencia debieron de caer entonces en manos del rey don Pedro. ¿Pudo servir Florencia como dama en la cámara de la reina Blanca de Borbón? No parece imposible, ciertamente: la prisión de la reina Blanca era estrecha, nos dice Ayala ("e pasó grand penitencia en las prisiones do estovo, e sufriólo todo con muy grand paciencia": Cr.P., año 12, 1361, cap. 3), y en ella no entraban hombres ("ca nunca dexaban a ningund ome entrar do ella estaba": idem), lo que hace pensar que la presencia junto a la reina de algunas damas no sería desacostumbrada - plausible, en todo caso. Tanto la reina Blanca de Borbón como Isabel de Lara murieron en 1361; el hecho de que Ayala agrupe sus muertes en un solo capítulo de su crónica sugiere cierta relación entre ellas (y de hecho, ambas damas no se hallaban alejadas en el momento final, pues de Blanca se nos dice que su última prisión fue en Medina-Sidonia, y la de Isabel de Lara, en Jerez de la Frontera). Bien pudo ser que la joven Florencia hubiera sido dama de la reina y hubiera sabido algo como testigo fiable de su muerte, tal como se nos informa en la crónica de Froissart. Huyó entonces a los dominios de Gastón Febo - contando con la ayuda más tarde recompensada por Juana Manuel y Enrique II, de acuerdo con la noticia que Salazar recoge -, y allí casó con Pierre de Béarn.

La historia se volvería en este punto bastante transparente, y quedaría suficientemente aclarada la pretensión de Florencia y Pierre de Béarn a Vizcaya en virtud de la sucesión en los supuestos derechos del fallecido infante Juan de Aragón, casado con Isabel de Lara, si no fuera porque en los documentos pontificios que editamos en

${ }^{25}$ Sobre las implicaciones literarias e incluso simbólicas de este onírico episodio, cfr. ZinK, M.: "Froissart et la nuit du chasseur", Poétique, 41 (1980) 60-77 ; Grisward, Joël-Henri: "Froissart et la nuit du loup-garou. $\mathrm{La}$ «fantaisie» de Pierre de Béarn: modèle folklorique ou modèle mythique?", en Le modèle à la Renaissance (J. Lafond, ed.), París, 1986, pp. 21-34; Huot, Sylvia: "Unruly Bodies, Unspeakable Acts : Pierre de Béarn, Camel de Camois, and Actaeon in the Writings of Jean Froissart", Exemplaria : A Journal of Theory in Medieval and Renaissance Studies, 14/1 (2002) 79-98.

26 “elle dist à son mari: «Monseigneur, je n'aray jamais santé jusques à ce que j'aye esté en pelerinage à Saint Jaques. Donnez moy congié d'y aler, et que je y porte Pierre mon filz et Andrienne ma fille, je le vous requier». Messire Pierre lui accorda trop legierement. La dame se parti en bon arroy et emporta et fist porter devant li tout son tresor, or, argent et joyaulx, car bien savoit que plus ne retourneroit, mais on ne s'en prenoit point garde. Toutefois fist la dame son voyage et pelerinaige, et prinst achoison d'aler veoir le roy de Castille son cousin, et la royne, et vint devers eulx. On lui fist bonne chiere. Encores est elle là, et ne veult point retourner ne renvoier ses enfants": FroISSART, Ibidem, p. 193. 
nuestro apéndice se hace mención inequívoca, como consorte de Pierre de Béarn, no a Florencia, hija del infante Juan de Aragón, sino a Juana Núñez, hija de Juan Núñez (de Lara) y de María (de Haro) condesa de Vizcaya, de la que adicionalmente se dice que era viuda de don Tello, hermano de Enrique II. Debe asimismo tenerse en consideración que Ayala omite referirse a cualquier descendencia de Isabel de Lara y el infante Juan de Aragón, e incluso recoge sin contradecirla la ya citada frase en que la condesa viuda de Alençon afirmaba que ya no quedaban herederos de la rama del tercer Juan Núñez de Lara ${ }^{27}$. Así pues, se trataría aquí de verificar la confianza que merecen las noticias aportadas por Froissart, y decidir cuál es la relación existente entre su relato y las tres cartas pontificias de 1373 a las que hacemos referencia.

El embrollo parece realmente difícil de resolver y deja muchos interrogantes abiertos: ¿pudo mediar error en la recogida de datos que tuvo lugar en la cancillería pontificia al redactar las cartas que presentamos en nuestro apéndice?, ¿pudo haber voluntad de engaño por parte de Pierre de Béarn, pretendiendo que su mujer Florencia era en realidad Juana de Lara?, nada de ello puede, en este punto, sino conjeturarse, en espera de que otras aportaciones arrojen nueva luz sobre los interrogantes que planteamos en el presente estudio.

\section{CONCLUSIÓN}

Resulta verdaderamente difícil extraer conclusiones positivas de cuanto hemos conjeturado y expuesto en las líneas precedentes. El asunto es en verdad complejo, y nos deja una impresión dominante de perplejidad, lejos de cualquier certeza. Juana de Lara, la condesa viuda de Alençon, la reina Juana Manuel, e incluso Isabel de Lara a través de su hija Florencia, se nos han cruzado en el camino mientras tratábamos de esclarecer la incorporación de Vizcaya al dominio directo de la corona castellana, como otras tantas depositarias, legítimas o virtuales, a la herencia de este señorío o condado. Lo referente a Juana Manuel y a Marie d'Espagne parece suficientemente aclarado. Las dudas llegan cuando se trata de la posible descendencia de Isabel de Lara, o de la suerte de su hermana Juana. Acerca de esta última, cabe afirmar que desde cualquier punto de vista, sólo existe la disyuntiva lógica entre dos únicas posibilidades: o Juana de Lara sobrevivió a la prisión en que la tuvo el rey Pedro, o no; a partir de esta bifurcación, tratar de explicar lo que realmente sucedió se vuelve más y más difícil. Como ya hemos reconocido, no es fácil decidir cuál de nuestras dos hipótesis principales, la de la verdadera Juana que rehizo su vida y con el tiempo volvió a aspirar a la herencia de Vizcaya, y la de la impostura de la pretendiente falsa, resulta más arriesgada y comprometida.

Ambas son, en último término, inverificables, al menos disponiendo de la información que manejamos en el presente estudio. En cualquier caso, convenía exponerlo todo, datos y conjeturas, con cierto detenimiento y extensión, aunque sólo fuera por el interés intrínseco de un curioso enigma histórico preñado de consecuencias, y también con la esperanza de que nuevas investigaciones y nuevos hallazgos documentales permitan algún día desentrañar la clave de este peculiar "misterio".

\footnotetext{
27 "Todos estos fijos e fijas de don Juan Núñez morieron sin dexar fijos herederos de sus cuerpos": LóPEZ De Ayala, P.: Cr.E-II, año 8, 1373, cap. 10.
} 


\section{APÉNDICE DOCUMENTAL}

1373, mayo 26, Sorgues.

Gregorio XI pide a Enrique II de Castilla que restituya el señorio de Vizcaya a cierta Juana Núñez, que dice ser la viuda de su hermano Tello.

Città del Vaticano, Archivum Secretum Vaticanum $(A S V)$, Registra Vaticana (Reg. Vat.), vol. 269, fol. 169 v.

Carissimo in Christo filio Henrico, Regi Castelle et Legionis illustri, salutem et cetera. Ad illa, te fili carissime, libenter inducimus, ac precibus exhortamur, que honestatem sapiunt teque in conspectu Regis Eterni reddere ualeant gratiosim. Sane nuper, ex conquestione dilecte in Christo filie nobili mulieris Johanne, quondam Johannis Nugitz comitis, et quondam Marie eius uxoris, comitisse de Vizcaya, nate Calaguritane diocesi, precepimus quod licet ipsa huiusmodi suis parentibus in comitatu de Vizcaya, dicte diocesis, successerit, ac comitatum ipsum, post dictorum parentum suorum obitum, una cum quondam don Telli de Castella, fratri tue, eius marito, aliquandum possederit pacifice et quiete, tamen postmodum dicto donaelli [sic, por: don Telli] uitafuncto, tua serenitas, seu gentes tue, comitatum ipsum occupastis, et nunc tenetur occupatum, in ipsius Johanne ac dilecti filii nobili uiri Petri de Bearnio, eius uiri, preiudicium non modicum et grauamen. Cum autem serenitatem ipsam non deceat talia, si uera sunt, facere, seu aliquatenus tollerare, eandem serenitatem tuam rogamus et hortamur attente, quatenus pro nostra et apostolice sedis reuerentia, ac etiam tui honoris et pietatis intuitu, prefatum comitatum eidem Johanne, si ad eam pertinet, cum ipsa, sicut asseuerit, parata sit excellentie regie facere et prestare homagium et fidelitatis iuramentum, liberaliter restituere seu restitui facere sinceritas tua uelit. Ita quod Omnipotentem Dominum tibi constituas propicium, nosque proinde deuotionem tuam non immerito commendare possimus. Datum apud Pontemsorgie, Auinionensis diocesis, vii kalendas junii, anno tertio. 
1373, mayo 26, Sorgues.

Gregorio XI pide a la reina Juana Manuel de Castilla que interceda ante su esposo Enrique II por la restitución del señorío de Vizcaya a quien dice ser Juana, viuda de Tello.

ASV, Reg. Vat. 269, fols. 169v-170r.

Carissime in Christo filie Johanne, Regine Castelle et Legionis illustri, salutem et cetera. In fauorem dilecte in Christo filie nobilis mulieris Johanne, quondam Johannis Nugitz comitis, et quondam Marie, eius uxoris, comitisse de Vizcaya, nate Calaguritane diocesi, carissimo in Christo filio nostro Henrico, Regi Castelle et Legionis illustri, uiro tuo, scribimus ut comitatum de Vizcaya qui, ut assereuit, ad ipsam Johannam pertinet, restituat et restitui faciat atque mandet. Cum autem in premissis fauor tuus sit plurimum oportunus, excellentiam regiam rogamus et hortamur attente, quatenus pro nostra et apostolice sedis reuerentia, ac etiam pietatis intuitu, apud eundem uirum tuum, quod nostris in hac parte precibus annuat, $[170 r]$ opem des, et operam efficaces. Datum ut supra.

1373, mayo 26, Sorgues.

Gregorio XI encomienda a su legado en España, el cardenal Guido de Boulogne, el asunto de la restitución del señorío de Vizcaya.

ASV, Reg. Vat. 269, fol. 170v.

Venerabili fratri Guidoni, episcopo Portuensi, apostolice sedis legato, salutem et cetera. In fauorem dilecte in Christo filie nobilis mulieris Johanne, quondam Johannis Nugitz comitis, et quondam Marie eius uxoris, comitisse de Byzcaya, nate Calaguritane diocese, carissimo in Christo filio nostro Henrico regi, et carissime in Christo filie nostre Johanne regine Castelle et Legionis illustribus scribimus, prout continet cedula presentibus interclusa. Cum autem in premissis fauor tuus sit plurimum oportunus, fraternitatem tuam, et cetera, usque 'reuerencia', ac etiam pietatis intuitu, apud eosdem regem et reginam, quod nostris in hac parte precibus annuant, opem des et operam efficaces. Datum apud Pontemsorgie, Auinionensis, et cetera, ut supra. 